\title{
Mitral valvotomy at Birendra Military Hospital
}

\author{
Rajbhandari GL* \\ *Birendra Military Hospital, nepal
}

\section{INTRODUCTION}

Shree Birendra Hospital is a 400 bedded referral military hosital situated in Kathmandu Nepal. It has been providing medical \& Surgical services to regular and retired army personnel and tieir families, for the last 75 years. It also provides specialized services in medical and surgical sub specialties like Neuro Surgery, Cardio-thoracic surgery, Uro-surgery. Gastro-enterology surgery, Laproscopic surgery, Cardiology, Gynaecology, Neuro-Psychiatry, Nephrology \& various other specialities. Diagnostic facilities are provided by advance Diagnostic facilities are provided by advance pathology and Radiology deparments (MRI CT scan, Bronchoscopy, G.I. Endoscopy, Echo-cardiocardiography etc).

Cardio-Thoracic Surgery unit started its services in this hospital from the year 2050 B.S. (1994 A.D) The first Cardiac surgery started with a successful operation for a patient with mitral stenosis by closed heart surgery (closed mitral valvotomy) in the year 2051 B.S, 23 Chaitra; (6th April, 1995 A.D.). cardiac problems are not usually encountered among regular army personnel due to strict medical screening during army recruitment so cardiac surgery is generally required for family members of the serving \& retired army personnel instead. 1

\section{MATERIALS AND METHODS}

From 2051 BS to 2057 BS (1995 to 2000 A.D.). 7 patients underwent Closed Mitral Volvotomy (CMV), among them 6 were female and 1 male. Their age ranged from 15 years to 40 years and there was no operative mortality. 2,3 The selection criteria for CMV was patient with tight mitral stenosis with Mitral Valve Area (MVA) less than or equal to $1 \mathrm{~cm} 2$ on Echocardiography, sinus rhythm, no clot in LA, ASO titre negative, no significant calcification of mitral Valve or mitral Regurgitation. Patients in clinical classification of NYHA class III to IV. 4,5

\section{RESULTS}

The routine surgical procedure was mitral volvotomy with digital commisurotomy followed by Tubbs dilator application up to $2.5 \mathrm{~cm}$. the result of $\mathrm{CMV}$ wassatisfactory clinically \& there were no significant post surgical mitral regurgitation. There was significant clinical improvement of patient post operatively \& patient were clinically in NYHA class I to II. There was no case of mitral re-stenosis after 4 years of CMV rest of 6 patients were clinically doing well during follow up of 5 years of operation. 6,7,8

On post operative Echocardiography MVA was found to be $1.8 \mathrm{~cm} 2$ to $2.2 \mathrm{~cm} 2$. one patient with post operative CMV developed mitral re-stenosis and had Percutaneous Transvenous Mitral Commissurotomy (PTMC) done at Shahid Gangalal Heart Centre in 2061.

\section{DISCUSSION}

History of mitral valvotomy starts back in 1923 AD when Levin \& Cuttler successfully performed closed mitral valvotomy in an 11 year old girl with severe mitral stenosis. With the development of Heart Lung Machine Lillehei \& Kirklin performed open mitral valvotomy in 1955. since 1990 s with advancement of invasive cardiology successful percutaneous mitral commissurotomy was started in many centres of world. With the beginning of the Maoist insurgency from 2052 B.S. and with the involvement of nepal Army in insurgency control movment from 2058 B.S; this hospital was involved in management of insurgency casualties of Nepal army personnel \& Civillans. Thus the cardio thoracic surgical unit was involved in the management \& surgery of thoracic trauma patient during that period.

During last few years with the advancement of invasive cardiology \& development of non surgical Percutaneous Transvenous Mitral Commisurotomy (PTMC) in Nepal, most of the patients with mitral stenosis were referred to Shahid Gangalal Heart Centre. With the availability of non surgical PTMC, the oldest cardiac surgical procedure closed mitral valvotomy is almost obsolete in most of cardio-thoracic centres. Now closed mitral valvotomy is done only as an emergency surgical procedure in few cardio-thoracic centres in the world.

\section{REFERENCE}

1. Rajbhandary G.L. 1994. Mitral Valvotomy an Oldest Cardiac Surgical Procedure for Mitral Stenosis. MJSBH, Vold 2, No. 2 1999, Page no 22 to 28

2. Ellis LB etal 1973,15 to 20 years study of 1000 patients undergoing Mitral Valvotomy. Circulation, XL to 3724 consecutive patients Circulation 1983, 68 (5) 891

3. Goldman ME1986, Intra Operation Echocardiography for evaluation of Valvular regurgitation Experience in 263 patients Circulation 1986, 74, Supp. 1. 1-14

4. Anonymous 1973, Criteria Committee of New york Heart Association Nomenclauture criteria for diagnosis of disease of heart \& great Vessels. 7th Ed. Little Brown, Boston 1773, 286

5. Aventura AP, 1986, Closed Mitral Valvotomy, Rob \& Smiths Operative Surgery, Cardiac Surgery, Ed. Jamieson SW, Shumay NE, Butter Worth, London, 1986, 399.

6. Logan \& Turner 1959, surgical Treatment of Mitral Stenosis with particular reference to Mechanical Dilator. The lancet 1959,2 874

7. Rajbhandary G.L., Khan JS, Chema MA, 1994 early results of Closed Mitral Valvotomy \& open Mitral Valvotomy for Juvenile Mitral Stenosis in Pakistan. Proceedings of First international conference of Society of Surgenos of Nepal, Kathmandu, 1994

8. Loya YS 1991, Ballon Mitral Valvotomy, Pak J. Cardio, 1991, 41

9. Maskey A. 2005 Interventional Procedure at Sahid Gangalal National Heart Center 10th Anniversary Annual issue, 25 